\title{
Detection of methane using multi-walled carbon nanotubes
}

\author{
J KATHIRVELAN ${ }^{1}$ and R VIJAYARAGHAVAN ${ }^{2, *}$ \\ ${ }^{1}$ School of Electronics Engineering, VIT University, Vellore 632 014, India \\ ${ }^{2}$ School of Advanced Sciences, VIT University, Vellore 632 014, India
}

MS received 19 September 2014; accepted 16 March 2015

\begin{abstract}
A sensor for detecting and estimating methane using multi-walled carbon nanotubes (MWCNTs) as the sensing element has been developed for the first time. Silver electrodes have been ink-jet printed on glass substrate over which MWCNT is brush coated to fabricate the sensor element which is of chemoresistive type. The sensitivity of the sensor (increase in the resistance of the sensor on exposure to analyte) increases linearly with concentration of methane and a maximum sensitivity of about $20 \%$ has been observed for $160 \mathrm{ppm}$ of methane. A prototype device has been fabricated with this sensor and tested for its performance. It could be used to detect methane on site.
\end{abstract}

Keywords. Multi-walled carbon nanotubes; chemoresistive; methane sensor; ink-jet printing.

\section{Introduction}

Sensors find applications in various fields of scientific and engineering disciplines ranging from controlling and monitoring chemical, machining process to biomedical devices. ${ }^{1-4}$ Chemical sensors especially, gas sensors find potential applications in hospitals, industries and also for environmental monitoring. ${ }^{5,6}$ Hydrocarbon gases constitute mostly flammable fuels which are difficult to be detected as these are colourless and odourless. Hence, the development of gas sensors for hydrocarbon gases is of importance. ${ }^{7-9}$

Methane is being detected employing gas chromatographic techniques, NDIR sensors, fibre optic sensors, noncatalytic thermal sensors, electro-chemical sensors. ${ }^{7,10-19}$ All these techniques are laboratory based and not cost effective. In order to develop a low cost method, a reversible chemoresistive gas sensor using multiwalled carbon nanotubes (MWCNTs), applicable for the detection of methane on site has been fabricated. Our fabrication method of sensor element has not yet been reported.

Single-walled carbon nanotube (SWCNT) has been extensively used for gas sensing since it was discovered by Iijima and Ichihashi in 1993. ${ }^{20}$ Carbon nanotubes (CNTs) have been used for the detection of gases such as ethylene and ammonia in ppm levels with high sensitivity even at room temperature. ${ }^{21-24}$ SWCNT has additional and beneficial physical, chemical and mechanical properties. ${ }^{25-28}$ MWCNT is a multi-layer of rolled graphene ${ }^{29}$ which has higher surface-to-volume ratio than SWCNT. ${ }^{30}$

Here, we present a reversible chemoresistive sensor using MWCNTs capable of detecting ppm levels of methane with high sensitivity. The sensing mechanism is based on the

\footnotetext{
*Author for correspondence (rvijayaraghavan@vit.ac.in)
}

removal of electron from CNTs upon exposure to analyte and this leads to an increase in the resistance of CNTs as shown schematically in figure 1 . This principle is used widely for gas-sensing applications. ${ }^{21,31}$

\section{Experimental}

\subsection{Characterization of MWCNTs}

MWCNT dispersion of $0.5 \mathrm{wt} \%$ in water was purchased from Iolitech Ionic $\mathrm{GmbH}$, Germany and has been characterized by field emission scanning electron microscopy (FESEM), Fourier transform infrared (FTIR) and Raman spectra. FESEM image (figure 2) confirms the presence of MWCNT with average diameter of about $40 \mathrm{~nm}$.

The peaks at wavenumbers of 1641 and $3444 \mathrm{~cm}^{-1} 32$ in FTIR spectrum reveal the presence of MWCNTs on the coated film. Raman spectrum (figure 3) with peaks at 1287 and $1600 \mathrm{~cm}^{-132}$ confirm signatures of MWCNT in coated film.

\subsection{Preparation of silver electrodes}

A $2.5 \times 2.5 \mathrm{~cm}$ glass slide was cleaned chemically and patterned with silver electrode by silver nanoconductive ink using piezohead-based drop on demand ink-jet printing technology (Epson T60) with electrode width of 1,2 mm of interelectrode distance and thickness of $10 \mu \mathrm{m}$. The glass slide was dried in an hot air oven for $1 \mathrm{~h}$ at $120^{\circ} \mathrm{C}$. The electrode printed is shown in figure $4 a$.

\subsection{Deposition of MWCNT}

MWCNT dispersion solution was concentrated until the volume of the solution is reduced to $1 / 4$ of its initial value. 


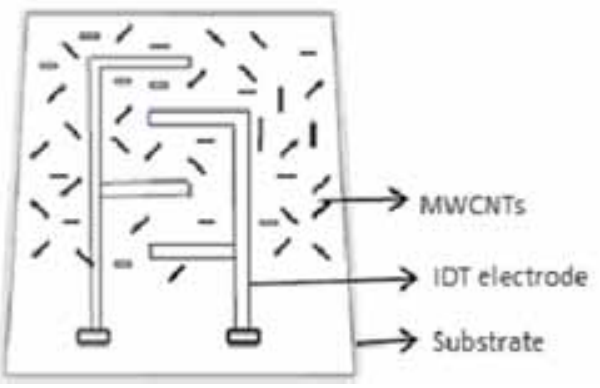

(a)

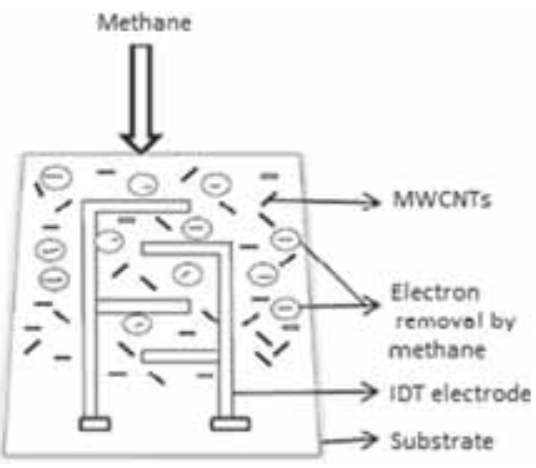

(b)

Figure 1. Schematic of methane detection by MWCNT chemoresistive sensor: (a) ambient and (b) exposed to methane.

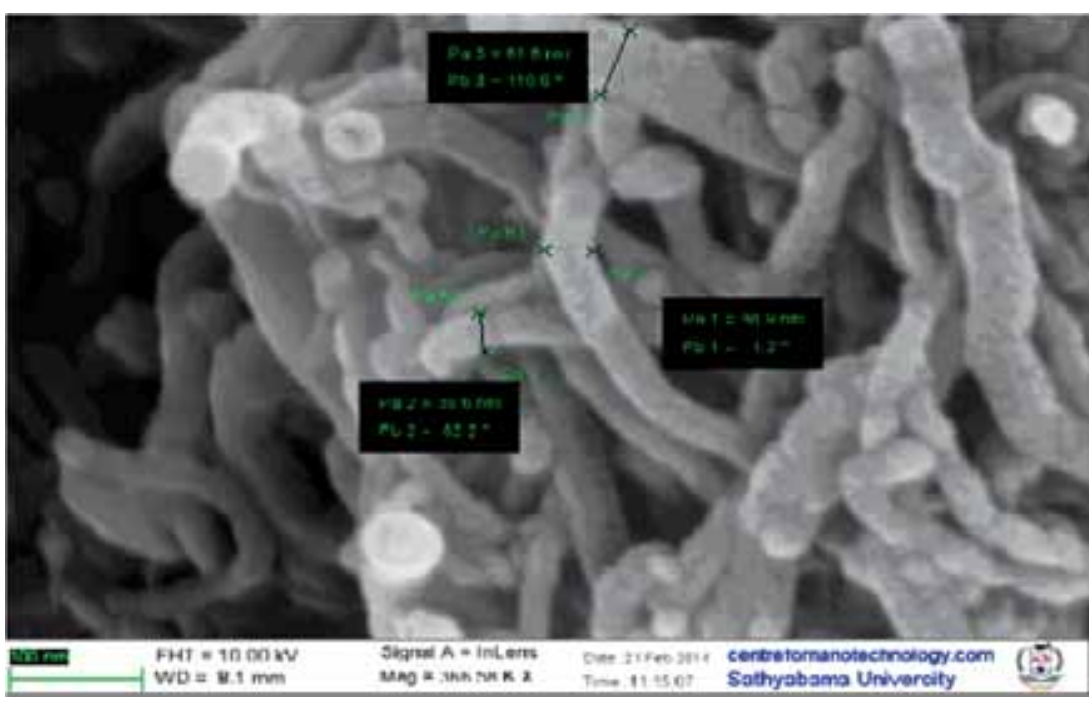

Figure 2. FESEM image of MWCNT bundles.

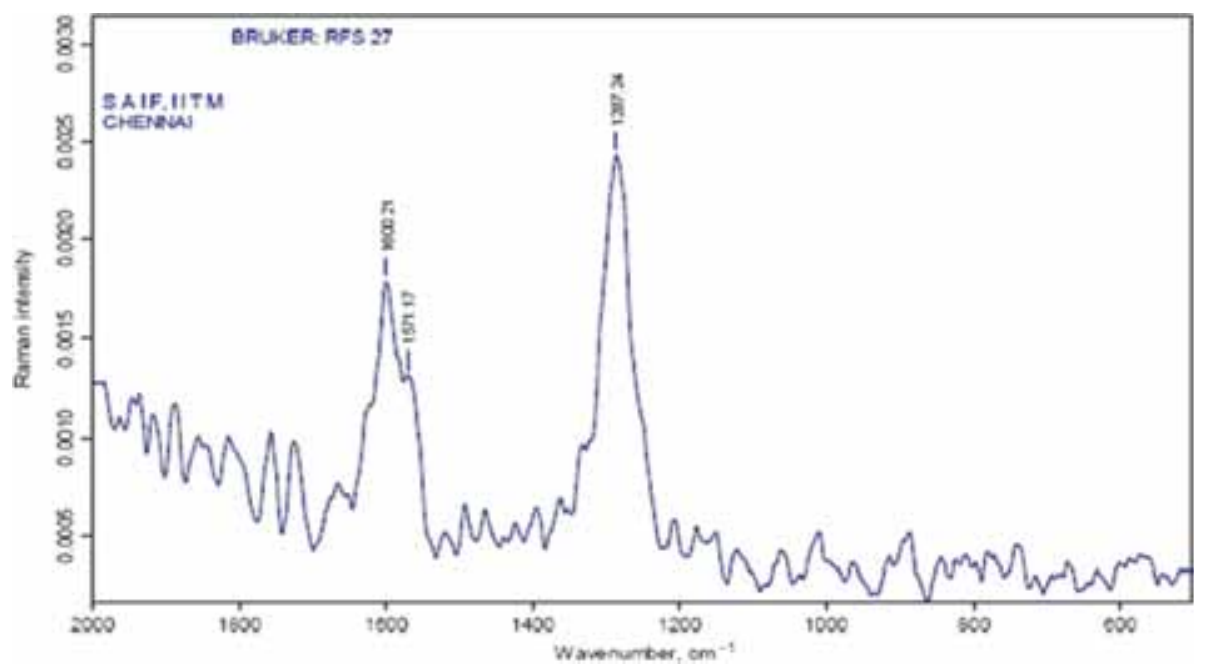

Figure 3. Raman spectrum of MWCNT. 
The concentrated MWCNT dispersion is then coated on the silver IDT electrode using brush coating and dried in hot air oven at $100^{\circ} \mathrm{C}$ for $30 \mathrm{~min}$. The thickness of the film was found to be $10 \mu \mathrm{m}$ (figure $4 \mathrm{~b}$ ). Silver contacts with silver leads were provided for measurements.

\subsection{Gas test cell set-up}

The test cell is made of air tight acrylic chamber of dimensions $(4 \times 4 \times 3 \mathrm{~cm})$ enclosing the sensor element at the

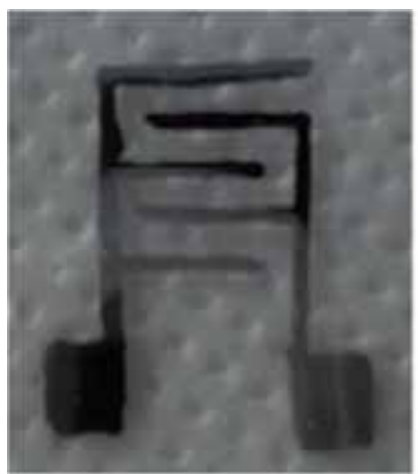

(a)

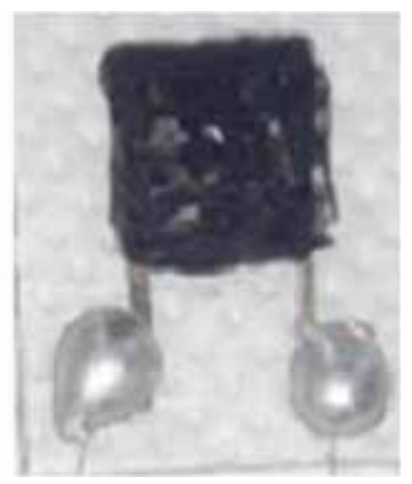

(b)
Figure 4. Sensing element fabrication: (a) silver IDTs printed on glass substrate and (b) deposition of MWCNT on glass slide printed with silver IDT electrodes (magnified image).

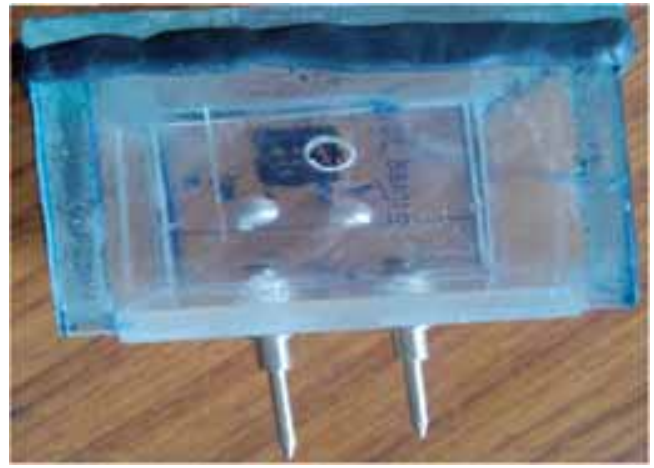

Figure 5. Prototype gas test cell. centre. The silver electrodes of the sensing element is cold soldered with flexible silver wires connected to copper leads fixed on to the front side of the chamber (figure 5). The resistance of the sensing element is measured using $61 / 2$ digit Agilent multimeter (Model: 34401A).

The test cell consists of two openings, one for the gas inlet positioned over the chip and other for the gas outlet which is air tightened. Methane was injected into the gas test cell by means of gas collecting microsyringes.

\subsection{Calibration of sensor}

MWCNT sensor element used in this study was calibrated with pre-calibrated standardized methane gas of different (known) concentrations purchased from M/s. Chemtron Science Laboratories Ltd, India. Reproducibility is confirmed by repeated measurements.

The calibration curve of our sensor is depicted in figure 6 . Percentage sensitivity of the sensor is calculated using equation (1) and percentage sensitivity/ppm of the sensor is calculated from the slope of the calibration curve using equation (2). Calibration curve indicates linearity, sensitivity and repeatability

$$
\begin{aligned}
& \% \text { Sensitivity }=\left(-\frac{\Delta R}{R_{0}}\right) \% \\
& =\left(-\frac{\left(R_{\text {air }}-R_{\text {analyte }}\right)}{R_{\text {air }}}\right) \times 100, \\
& \% \text { Sensitivity } / \mathrm{ppm}=\left(\frac{\Delta Y}{\Delta X}\right)=0.122 .
\end{aligned}
$$

\section{Results and discussions}

The sensor element has a resistance of $1.0874 \mathrm{k} \Omega\left(R_{\text {air }}\right)$ at room temperature in air. Pure methane gas was diluted with air using peristaltic pump to vary its concentration to obtain unknown samples, which is then injected into the test cell.

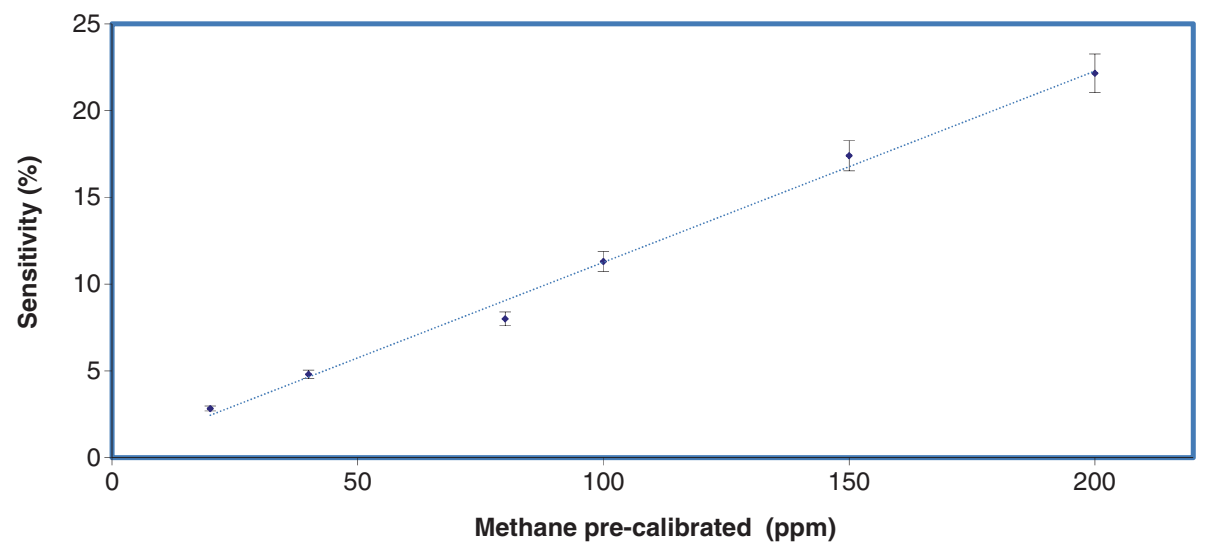

Figure 6. Calibration of MWCNT methane sensor. 


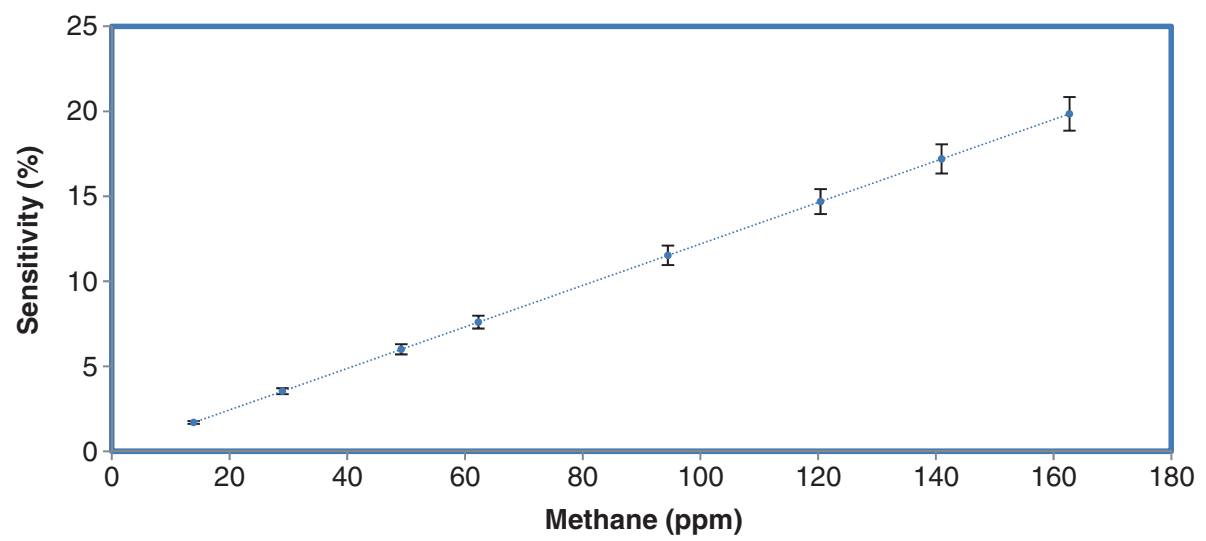

Figure 7. Sensitivity $v s$. methane concentration (unknown).

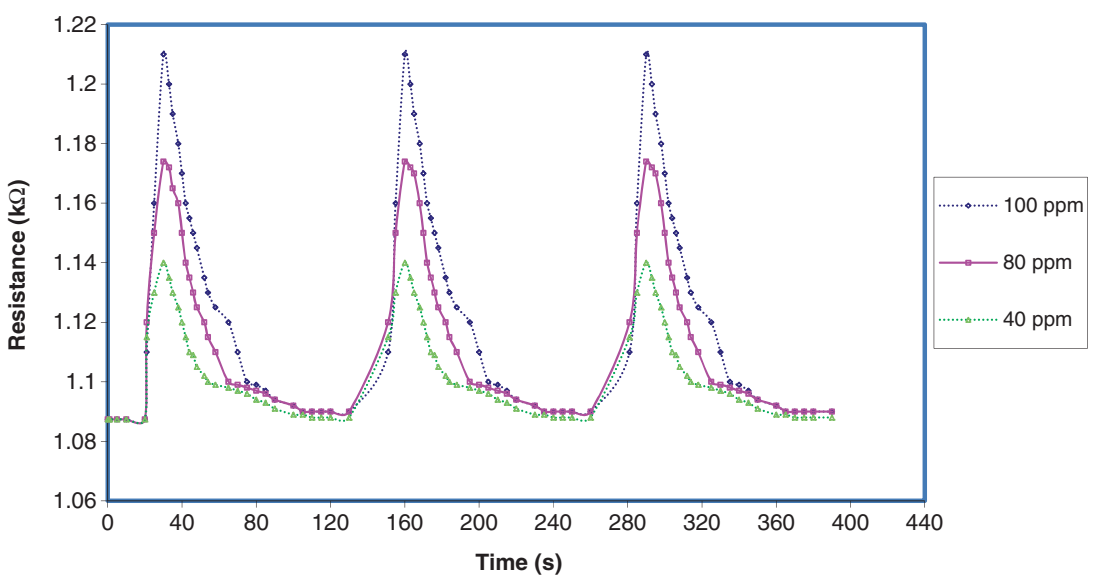

Figure 8. Response of MWCNT sensor with methane gas concentrations.

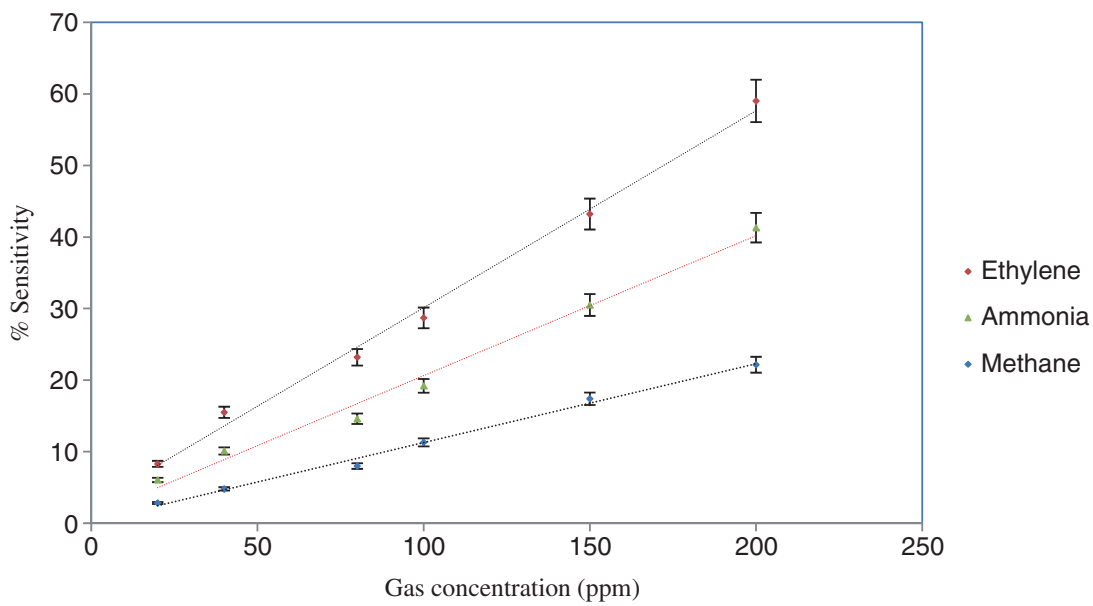

Figure 9. Sensitivity plots for three different analytes.

\subsection{Sensitivity}

The sensor instantaneously recorded an increase in resistance and this change of resistance is found to be directly proportional to the concentrations of methane. Sensitivity defined by equation (1) is plotted against concentration of sample methane (figure 7). The unknown (sample) methane concentration is calculated from equation (2) of the calibrated plot. 


\subsection{Response}

Figure 8 shows the response time of the sensor element to be $10 \mathrm{~s}$ and the recovery time to be $60 \mathrm{~s}$ for three different concentrations. The sensor action is reversible. The output response of the sensor is linear with $\pm 5 \%$ of accuracy.

\subsection{Selectivity}

Selectivity is a major limitation of chemical sensors. ${ }^{23,33}$ However, from the slopes of linear plots of sensitivity vs. concentration, one will be able to distinguish the different types of analytes as shown in figure 9, to some extent. Also neural network patterns of different analytes can be of use for selectivity distinction. ${ }^{34-39}$

\section{Conclusion}

This work reports the fabrication of methane sensor prototype device using MWCNT sensor element on ink-jet printed silver IDT electrodes. It shows reversible sensing of methane and its response, recovery, sensitivity, linearity and reproducible characteristics of the sensor are favourable for potential applications.

\section{References}

1. Wang Q and Arash B 2014 Comput. Mater. Sci. 82350

2. Spichiger-Keller U K 2003 Chemical sensors and biosensors for medical and biological applications (Weinheim: WileyVCH Press) 3rd ed

3. Soloman S 2009 Sensors and control systems in manufacturing (New York: McGraw-Hill Professional Press) 2nd ed

4. Brett C M A 2007 Pure Appl. Chem. 7911969

5. Fine G F, Cavanagh L M, Afonja A and Binions R 2010 Sensors 105469

6. Sekhar P K, Brosha E L, Mukundan R and Garzon F H 2010 Electrochem. Soc. Interface 1935

7. Quaranta F, Rella F, Siciliano P, Capone S, Epifani M, Vasanelli L, Licciulli A and Zocco A 1999 Sens. Actuators B $\mathbf{5 8} 350$

8. Sadek A Z, Choopun S, Wlodarski W, Ippolito S J and Kalantar-Zadeh K 2007 IEEE Sens. J. 7919

9. Meixner H and Lampe U 1996 Sens. Actuators B 33198

10. Heidt L E and Ehhalt D H 1972 J. Chromatogr. A 69103

11. Valentin J R, Carle G C and Phillips J B 1985 Anal. Chem. 57 1035

12. Liu J, Tan Q, Zhang W, Xue C, Guo T and Xiong J 2011 Measurement 44823
13. Tai H, Tanaka H and Yoshino T 1987 Opt. Lett. 12437

14. Xu S and Chen M 2012 Measurement 45325

15. Shemshad J 2013 Sens. Actuators B 186466

16. Culshaw B, Stewart G, Dong F, Tandy C and Moodie D 1998 Sens. Actuators B $\mathbf{5 1} 25$

17. Massie C, Stewart G, McGregor G and Gilchrist J R 2006 Sens. Actuators B 113830

18. Dorojkine L M 2003 Sens. Actuators B 8976

19. Karpov E E, Karpov E F, Suchkov A, Mironov S, Baranov A, Sleptsov V and Calliari L 2013 Sens. Actuators A 194176

20. Iijima $S$ and Ichihashi T 1993 Nature 363603

21. Esser B, Schnorr J M and Swager T M 2012 Angew. Chem. Int. Ed. 515752

22. Rigoni F, Drera G, Pagliara S, Goldoni A and Sangaletti L 2014 Carbon 80356

23. Quang N H, Van Trinh M, Lee B H and Huh J-S 2006 Sens. Actuators B 113341

24. He L, Jia Y, Meng F, Li M and Liu J 2009 Mater. Sci. Eng. B 16376

25. Ren F, Kanaan S, Majewska M, Keskar G, Azoz S, Wang H, Wang X, Haller G, Chen Y and Pfefferle L 2013 J. Catal. 309 419

26. Lee J H, Kang W-S, Najeeb C K, Choi B S, Choi S W, Lee H J, Lee S S and Kim J-H 2013 Sens. Actuators B 188169

27. Ndiaye A L, Varenne C, Bonnet P, Petit É, Spinelle L, Brunet J, Pauly A and Lauron B 2012 Thin Solid Films 5204465

28. Lee K, Lee J-W, Dong K Y and Ju B-K 2008 Sens. Actuators $B \mathbf{1 3 5} 214$

29. Xu K, Li Y, Xu C, Sengao J, Liu H, Yang H and Richard P 2013 Chem. Eng. J. 225210

30. Samarasekara P 2009 Chin. J. Phys. 47361

31. Mirica K A, Weis J G, Schnorr J M, Esser B and Swager T M 2012 Angew. Chem. Int. Ed. 5110740

32. Lehman J, Mauricio Terrones H, Mansfield E, Hurst K E and Meunier V 2011 Carbon 492581

33. Hafaiedh I, Elleuch W, Clement P, Llobet E and Abdelghani A 2013 Sens. Actuators B 182344

34. Baha H and Dibi Z 2009 Sensors 98944

35. Huang J R, Li G Y, Huang Z Y, Huang X J and Liu J H 2006 Sens. Actuators B 1141059

36. Di Lecce V and Calabrese M 2011 Describing non-selective gas sensors behaviour via logical rules. In fifth international conference sensor technologies and applications. Nice August 21-27 2011 (Nice: IARIA) p 6

37. Abdullah W F H, Othman M, Ali M A M and Shabiul Islam M D 2010 WSEAS Trans. Circuits Syst. 9700

38. Abdullah W F H, Othman M, Ali M A M and Shabiul Islam M D 2010 Am. J. Appl. Sci. 781

39. Kumar S, Yogi S N and Srivastava J K 2013 Int. J. Innov. Res. Sci. Eng. Technol. 123 